\title{
8 Paste Preparation
}

The paste is the material resulting from the clay with which the potter shapes the pottery vessels. Raw materials can be used directly as they appear in the clay source or, in contrast, certain substances may be added or removed from the clay. Thus, a potter can prepare different types of paste by using the same raw material. As can be seen, the preparation of the paste produces several changes in the original raw materials depending on the actions introduced by the artisans. The alterations occurring in the clay may differ according to the processes applied, which usually involve changes in the texture and the chemical and mineralogical composition of clays (Arnold, 2000; Blackman, 1992; Buxeda et al., 1995; Cuomo Di Caprio, 1985; Ortega et al., 2005; Orton et al., 1993; Sterba et al., 2009).

Few clays can be directly modelled without any previous preparation, but not all clays necessarily need to be modified. Thus, communities of potters related to ethnic groups such as the Bantu (Krause, 1984), the Kusasi (Calvo et al., 2013) or the Kalinga (Skibo, 1992) neither purify nor add temper to the clay. The direct use of alluvial clay sources linked to recent geological deposits is also well-known among many other communities, like in the area of Negros in the Philippines (Van der Leeuw, 1984), Congo (Mercader et al., 2000) and Mallorca (Albero and Puerta, 2011), as well as in pre-Hispanic pottery from Tabasco (Gallegos and Armijo, 2008).

\subsection{Clay Purification}

As already mentioned, clays usually require a basic purification process. Thus, the first change that usually occurs in the raw materials relates to the subtraction of certain components. There are many documented ethnographic examples (e.g., Arnold, 2000; Barley, 1994; Djordjevic, 2003; Druc, 1996; Gallegos and Armijo, 2008; García Rosselló, 2008; González Ruibal, 2005; Gosselain, 2008; Krause, 1984; Neupert, 2000; Spataro, 2004; Stark et al., 2000; Varela, 1990) where, before preparing the paste and adding any component to the clay, potters usually removed mineral and organic coarse materials (> $5 \mathrm{~mm}$ ) that are naturally present.

These mineral components and rock fragments often come from adjacent deposits that contaminate the clays. On the one hand, the presence of high amounts of coarse organic matter in the raw materials may promote ceramics with an excessive macro-porosity. On the other hand, volume changes occurring in the coarser nonplastic components during the manufacturing process can generate severe fractures that propagate from one margin of the vessel to the other. In this way, inclusions such as rock and plant fragments should be subtracted from the clay by hand or through levigation processes. 
It can be then assumed that, in many cases, ancient potters undertook at least the purification of the raw material through the removal of the surface layer of the clay source. Moreover, the inclusions coarser than the wall thickness intended for the vessels might also have been removed from the clay. We can approach the efforts intended for this action through the identification of larger rocks fragments remaining in the paste (Fig. 8.1 A), possibly after going unnoticed during the purifying process. Although these rock fragments could be also introduced when the paste is being mixed, their presence is evidence of the lack of interest of the potters to properly homogenize and refine the raw materials.

In some cases the purification is particularly relevant in the pottery production process. Then, potters decant the clay through levigation using water and tanks in order to eliminate the coarser fraction present in the sediment, thus increasing considerably the plasticity of the paste. If this procedure is very intense potters may obtain very fine-grained sediments that can be even used to make slips (Banning, 2005; Cooper, 2002; Echallier, 1984; Gibson and Woods, 1990; Stoltman, 2001; Tite et al., 1982). Levigation processes can be very difficult to detect in the fabric, even using optical methods such as the petrographic microscope. In any case, very finetextured pottery vessels with low amounts of fine sand and a low frequency of aplastic minerals are the most likely to have experienced this type of purification (Fig. 8.1 B). However, these textural features do not necessarily involve the application of these kinds of decanting processes, since very fine and plastic clays with only some fine sand and silt may be also naturally present in the environment (e.g., Albero and Mateu, 2012). In this sense, the presence of certain infrastructures such as tanks in the production areas is evidence of the application of levigation processes, although this type of structure is quite uncommon or difficult to identify in prehistoric archaeological records.
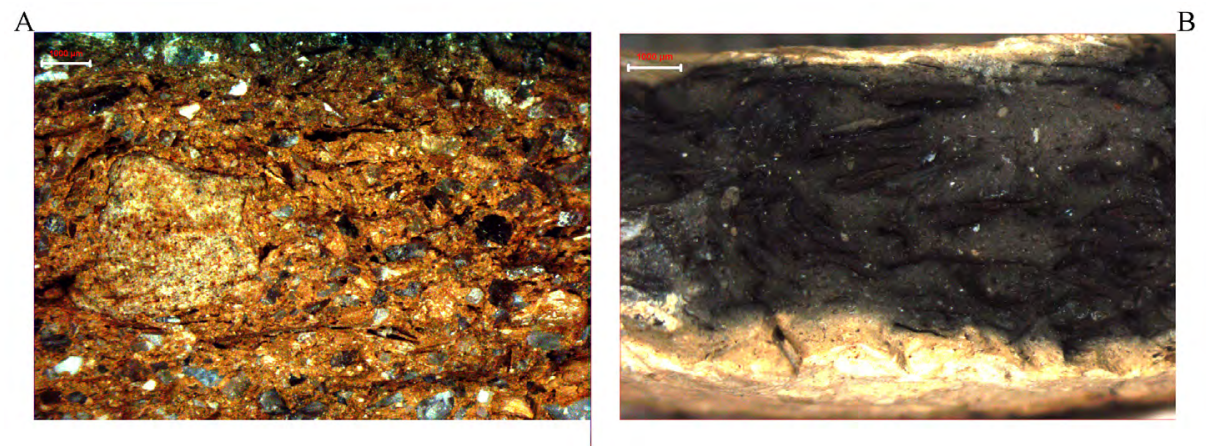

Figure 8.1: Photomicrographs taken with binocular microscope showing a A) ceramic section with a large rock fragment of several millimetres (Image width $=11.2 \mathrm{~mm}$ ). B) Fine-textured pottery related, perhaps, to an intense purification and levigation process (Image width $=11 \mathrm{~mm}$ ). 


\subsection{Temper Addition}

The addition of temper to the clay was one of the most widespread technological choices performed in the preparation of pastes in prehistoric pottery. This action greatly alters the properties of the original clay and largely determines the chemical, mineralogical, textural and petrological composition of the vessels. For example, potters can add tempers formed by calcium carbonate such as limestone, calcite or shells. Thus, the presence of these components in large amounts in the paste causes a significant increase in the concentrations of $\mathrm{CaO}$ and mineral phases such as calcite. Moreover, their addition involves the creation of a pottery fabric with particular physicochemical characteristics (Albero, 2011a; Bollong et al., 1993; Gibson and Woods, 1990; Hoard et al., 1995; Ortega et al., 2005; Potter et al., 2005; Shoval et al., 2006; Yankowski, 2008).

The addition of mineral temper provides a paste more consistent and reduces the amount of water required for hydration. This choice involves an intense interaction between the potter and the clays and tempers available, not only in the paste preparation stage but during the whole production process. In this sense, there is no perfect temper and each material has certain technical advantages and disadvantages. Moreover, two clays can be quite different from each other, so that, different clays may require diverse tempering strategies (Banning, 2005; Djordjevic, 2003; Orton et al., 1993; Riederer, 2004; Williams, 1982).

Several types of temper have been used in the ceramic production along time. Thus, many modern and ancient potters have commonly added minerals such as quartz or calcite to the paste. In this way, sands are traditionally used in ceramic production due to their high content in quartz and feldspars. Ethnographically their use is documented in such different places as the Thar Desert in Pakistan (Spataro, 2003) or in Ancash in Peru (Druc, 1996). Moreover, the use of sands as temper is observed from the Neolithic to the medieval period in archaeological ceramics from Britain (Tite et al., 2001; West, 1992; Woods, 1986). Also, regarding chronology, the addition of quartz-rich sands to the paste is typical in Roman fabrics from England (Freestone and Rigby, 1982; Mainman, 1982) and prehistoric ceramics from Alabama in America (Steponaitis, 1984).

In addition, different types of sedimentary, metamorphic and igneous rocks can be added to the paste as temper. These rock fragments are usually polymineralic (Gibson and Woods, 1990; Velde, 2005) and their intentional addition can be assumed when the grains have a bimodal distribution and are quite abundant in the paste as well as angular in shape. This is the case of rocks such as limestone, chert, sandstone, calcarenite, sedimentary or volcanic breccia, schist, phyllite, basalt, granite, etc. We must also consider that some fragments of these rocks may be unintentionally incorporated into the paste during the course of its preparation. In this sense, humans often use varied mineral resources for the creation of several types of artefacts whose waste may be present in the places where the potters prepare the pastes. In these 
cases, their presence is expected to be marginal and do not produce significant changes in the physical properties of the pottery.

Also biotic materials like shells, bone, hair or ashes can be added to the clay. Some archaeologists have even considered on the basis of ethnography (Vidal, 2011a) the use of organic substances such as blood, milk and other liquids as temper. References to the use of these uncommon types of temper are found, for instance, in Egypt (Matson 1989). One of the most widespread tempers is organic matter. Its use is well documented, among many other places, in the Neolithic pottery from the Carpathian basin in Hungary (Szákmany and Starnini, 2007), the Balkans (Spataro, 2002) or the Banat area in Romania, as well as in Anatolia, in the Levant and Belgium (Sestier et al., 2005).

In some pottery productions the addition of more than one temper to the paste is even observed (e.g., Livingstone-Smith, 2000; Riley, 1982; Williams, 1982). In this sense, it is common to record mineral tempers mixed with organic matter, for example in Pakistan (Spataro, 2004), South Africa (Bollong et al., 1993) and Niger (Gosselain, 2008). These kinds of mixtures are also found in pre-Hispanic ceramics from Chile (Uribe and Ayala, 2004) or the Late Iron Age in Mallorca (Albero, 2011a; Palomar, 2005).

Finally, the addition of substances of anthropogenic origin, such as crushed ceramics or grog, is also documented in archaeological ceramics from different periods and places. For example, the presence of grog is well-known, among many others, in Neolithic pottery from Granada in Spain (Capel et al., 1982), Roman pottery from England (Freestone and Rigby, 1982), during the Bronze Age in the Po River Valley (Brodà et al., 2009), in English beaker pottery (Russell and Williams, 1999), in prehistoric ceramics from the Orkney Islands (Williams, 1982), in pottery of the Woodland culture in the USA (Rafferty and Galaty, 2002), in Chalcolithic and Bronze Age ceramics from Fraga in Portugal (Jorge et al., 2009), during the Bronze Age in Hungary (Gherdán et al., 2007; Kreiter et al., 2007) and the Bronze and Late Iron Age in the Balearic Islands (Albero, 2011a; Gómez-Gras and Risch, 1999). This is also the most widespread temper during the Bronze Age in the north of the Iberian Peninsula where its addition seems restricted to storage and serving wares (Ortega et al., 2005). Finally, its use is also documented in many modern societies and ethnic groups such as the Bantu in South Africa (Krause, 1984), the Gamo in Ethiopia (Arthur, 2003), the Konkomba in Ghana (Albero et al., 2013) or the Kabyle Berbers in northern Africa (Balfet, 1984), as well as in other communities of potters documented in Tabasco in Mexico (Gallegos and Armijo, 2008), Niger (Gosselain, 2008) and Pakistan (Spataro, 2004), among many others.

Most communities of potters use specific recipes to prepare the ceramic pastes according to stipulated proportions of clay and temper, usually following volume measures (Banning, 2005; Albero, 2014). However, these rules are not always strictly accomplished in practice. The use of these recipes is well documented ethnographically, for instance the Bantu potters from South Africa add specific 
amounts of temper that are stipulated through handfuls and are thoroughly mixed with the clay (Krause, 1984). Also the potters of San Nicolas in Philippines use recipes consisting of sands that are added to the clay in a ratio of 1:3 (Longacre, 1999). The same occurs in communities of potters from the Ancash region in Peru, where the artisans mix specific proportions of different materials (Druc, 1996).

The addition of tempers can be inferred by means of optical observations of the fabric with petrographic microscope (Fig. 8.2) and sometimes also using a binocular microscope (Albero, 2011a; Albero, 2014). In this sense, the presence in the fabric of abundant elongated pores, often with charred organic matter inside, is usually an indication of the intentional addition of organic matter (Gibson and Woods, 1990). Organic inclusions naturally occurring in the clays are usually quite variable in size and have irregular shapes. In contrast, organic matter added as temper often has a less variable size and shape, especially if specific parts of a particular plant have been selected. In this sense, the observation of the plant imprints through optical methods can indicate whether there was a preference for using a particular part of a plant, or if both fine and coarse stems were selected following a regular pattern (Fig. 8.2 B). The analysis of the shape and the features of the voids may allow the identification of the parts of the plants (e.g., leaves, stems, seeds or roots) added to the paste. Indeed, in some cases the type of plant used as temper can also be broadly recognised. Unfortunately, the accurate identification of the species present in the ceramics on the sole basis of their imprints is usually very difficult to achieve. Precise identifications require conducting experimental reference collections focused on establishing the morphology and the location of the internal nodes and the traces that diverse organic materials and different parts of plants leave in the fabric after combustion (Mainman, 1982; Riederer, 2004; Sestier, 2005; Sestier et al., 2005; Smith and Trinkley, 2006; Velde, 2005).
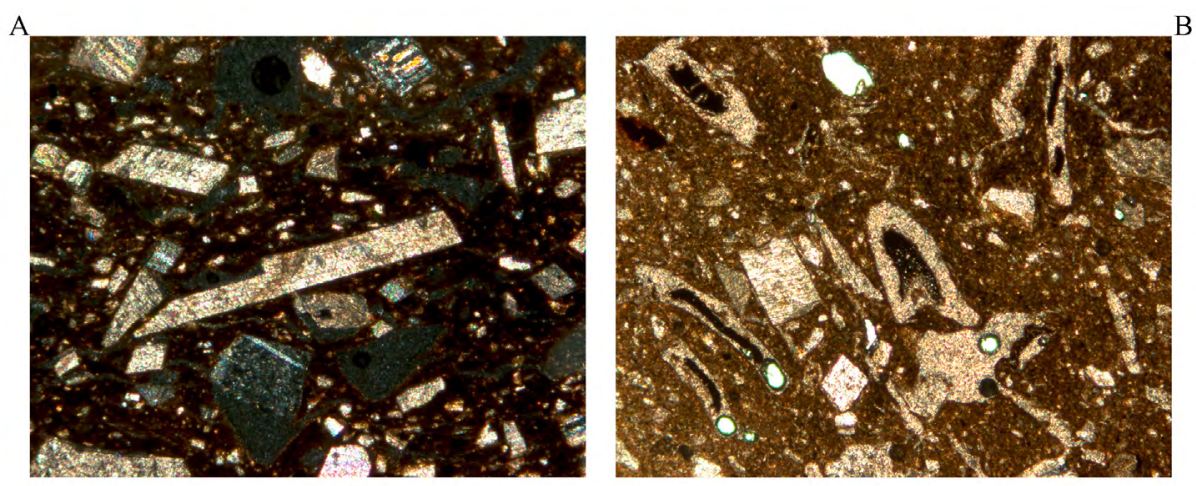

Figure 8.2: Thin sections photomicrographs showing tempers in ceramics (Image width $=870 \mu \mathrm{m}$ ). A) Fabric with abundant euhedral, prismatic and rhombic crystals of spathic calcite (XPL). B) Imprints of organic matter temper with some charred fibres and the presence of thin and thick stems (PPL). 
Unlike organic matter, the addition of minerals on archaeological ceramics is normally established through the angularity of the various components. The presence of euhedral and angular crystals with sharp edges and well-defined planes, which rarely occur in nature, permits to suggest that the minerals were crushed and intentionally added to the paste. In contrast, well-rounded particles may indicate that the non-plastic components were naturally present in the clay. Although this basic assumption may be useful up to a point, it is not advisable to establish direct connections exclusively based on the degree of sphericity of the grains. Thus, the type of component added and its natural formation characteristics and habits have to be fully considered in each particular case.

For instance, sometimes it is not possible to determine for certain whether the quartz crystals observed in the fabric relate to an intentional addition of beach sand or crushed sandstone, or whether they are already present in the clay (Fig. 8.3 A). Dealing with these kinds of issues, not to mention the accurate provenance of the sands used as temper, requires the development of specialised procedures involving the analysis of the several deposits located in different areas of the territory (Heidke, 2009; Heidke and Miksa, 2000). On the one hand, the presence of subangular quartz grains with sharp edges and conchoidal fractures may indicate that the inclusions are very close to their parental rock or source of origin. Therefore, the particles have not been subjected to intense erosion processes that alter their morphology. On the other hand, quartz grains observed in the fabrics can also be highly eroded, well-rounded and with a small size and high sphericity. These features suggest their natural occurrence in the clays; nevertheless, these traits can be also related to the intentional addition of sands, sandstones or other crushed rocks mainly formed by this mineral.

Thus, sometimes the potters add sands from streams or beaches in which the inclusions are very rounded by the erosive action of the wind and water. These characteristics give rise to confusion about the possible anthropogenic origin of the components because the particles can be interpreted as natural inclusions rather than as intentionally added temper. In these cases, the petrographic comparison between the coarse fraction and the clay matrix may be an efficient way to discern the provenance of these minerals. If the coarser grains are homogeneous in size and shape and the texture of the paste has also a bimodal distribution we may suggest that their presence is related to an anthropogenic origin (Gibson and Woods, 1990; Howard, 1982; Riederer, 2004; Stoltman, 2001).

Despite these constraints, it is crucial to determine the angularity, distribution, frequency, sorting and size of the different types of rocks and minerals present in the paste. Through these parameters, as well as by considering the nature of the different components, we are able to evaluate their possible intentional addition. Normally, pastes that possess high amounts of certain minerals or rocks with sharp edges and coarse grain sizes are the most likely to present added tempers (Banning, 2005; Gibson and Woods, 1990; Hoard et al., 1995; Orton et al., 1993; Riederer, 2004; Williams, 1982). 

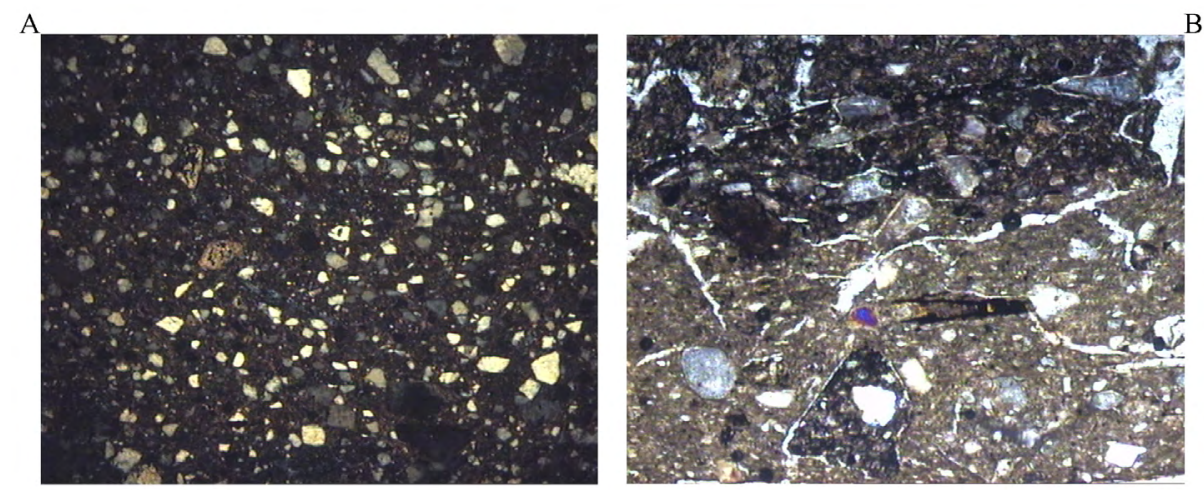

Figure 8.3: Thin section photomicrographs showing A) Fabric composed by sub-angular and subrounded monocrystalline quartz sand with a polymodal distribution (XPL; Image width $=4.6 \mathrm{~mm}$ ). B) Crushed ceramic fragments added to the paste as temper (PPL; Image width $=2.3 \mathrm{~mm}$ ).

Unlike many mineral components, the presence of grog in the paste (Fig. $8.3 \mathrm{~B}$ ) is almost always ${ }^{15}$ related to its intentional addition (Ots, 2008). In this sense, several studies (Cuomo di Caprio and Vaughn, 1993; Whitbread, 1986) have focused on the characteristic features present in crushed ceramics with the aim to distinguish grog from clay pellets or argillaceous rocks. Thus, parameters such as the orientation or the shape differentiate grog fragments from other particles naturally occurring in the clays.

The size, sorting and distribution of the temper provide some evidence about the effort intended to crush the rock and homogenize the paste. In this operation we must consider the hardness of each mineral, for instance in the Mohs scale, and its physical characteristics. For instance, calcite has a defining Mohs hardness of 3 and marked cleavage planes that make it easy to exfoliate. Hence, it suggests the need for low levels of activity compared to the effort required to crush harder rocks such as flint, granite or basalt. Each type of temper has a characteristic morphology when their cleavage planes are broken, giving place to more or less equant or elongated shapes along one axis, as well as more or less angular edges. In this way, in contrast to rounded grains, elongated and sharp crystals are more suited to favour higher adherence with the clay particles and the temper and, thus, to achieve a more consistent paste (Carter, 2002; Gibson and Woods, 1990).

The addition of mineral tempers such as spathic calcite slightly reduces the rate of water absorption in the paste (Albero, 2010). This behaviour should be related to a reduction in the percentage of clay minerals in the paste. The latter minerals have

15 It should be considered that the areas where the potters develop their activity may not be spotless. Therefore, small fragments of rocks, bones, ceramics or other materials that come in contact with the paste can be unintentionally incorporated. 
great capacity for water absorption and retention, effects that are significantly reduced through the addition of others substances that do not have this property. In this sense, the addition of temper can solve some harmful consequences involved in the use of highly absorbent clays. Simultaneously, the higher presence of non-absorbent materials reduces the amount of water needed to hydrate the paste. In short, the addition of temper has important implications in the whole manufacturing process as well as the several phases involved in the chaîne opératoire. Furthermore, this action largely determines the type of pottery obtained at the end of the production process.

The way in which clay and tempers are mixed and the paste is prepared can be representative of the potter's skills. On the one hand, there are pastes in which clay and temper are heterogeneously distributed in the matrix, thus evincing a poor clay mixing prior the addition of temper as well as subsequent failures in the mixture of clay and temper. Hence, these features indicate, first, the use of heterogeneous clays, and second, little interest and time investment for homogenizing the paste. On the other hand, fabrics that look very well kneaded and worked can also be observed, which show a fairly homogeneous distribution of the tempers along all the section. This higher homogeneity is also favoured by the addition of temper to fine-grained clay.

Finally, sometimes a laminar arrangement of the organic matter(Fig. 8.4 B) can be observed in most sections of archaeological ceramics by means of binocular and petrographic microscope. Some authors (Schiffer and Skibo, 1987), relate this feature to an inadequate paste preparation in which the temper was not properly mixed with the clay. This effect can be avoided through the addition of the organic matter to powdered and dry clay. Thus, this lamellar and fibrous structure may indicate that probably the clay was already wet when it was mixed with the organic matter.
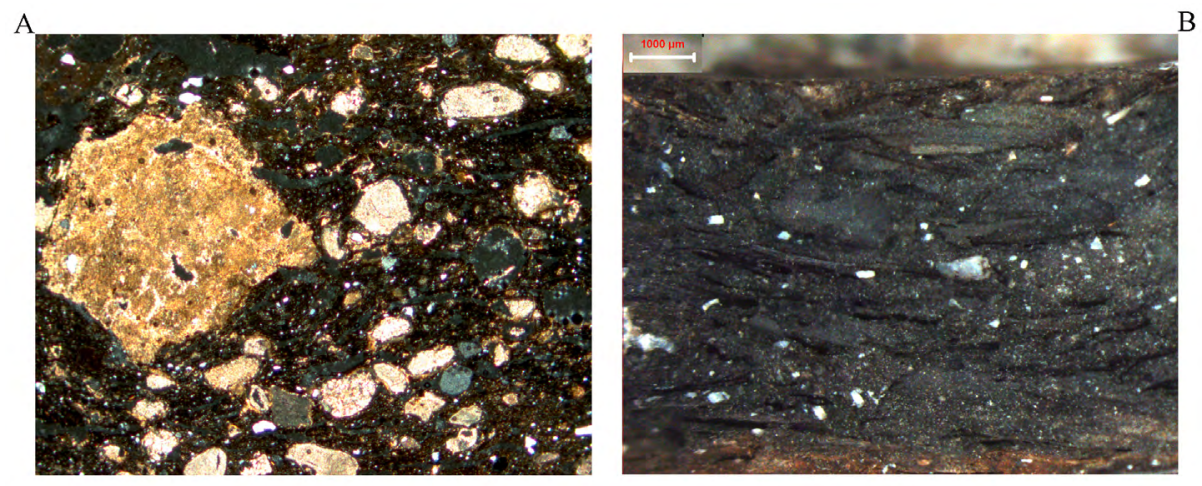

Figure 8.4: A) Thin section photomicrograph in cross polarised light showing crushed calcarenites added as temper along with a large fragment of sandy limestone (Image width $=2.7 \mathrm{~mm}$ ).

B) Photomicrograph taken with binocular microscope showing organic matter temper with a lamellar arrangement (Image width $=12.2 \mathrm{~mm}$ ). 


\subsection{Clay Mixing}

Some potters use only one type of clay while others mix two or more different types of clays. Thus, plastic clays are usually mixed with other coarser sediments in order to achieve suitable pastes and final products. This action is ethnographically documented, for example, in Kentri and Thraspano in Crete (Hein et al., 2004a; Riley, 1982), in Skala in Greece (Matson, 1989), in several barangays of Philippines such as San Nicolás (Longacre, 1999; Van der Leeuw, 1984), in Ancash in Peru (Druc, 1996) and in Quinchamalí in Chile (García Rosselló, 2008).

In the Mediterranean basin, the most common mixture results from the combination of non-calcareous red clays (called terra rossa) and very fine-grained Neogene or Cenozoic calcareous clays. Sometimes the terra rossa is the main basis of the mixture, while in others, as occurs in the manufacture of liquid storage vessels, the potters use marls as basic material and only optionally add red clay. In the latter case, the resulting pastes are characterized by a calcareous matrix with rounded nodules or veins formed by relicts of terra rossa (Basso et al., 2006; Hein et al., 2004a). Such technological choices are documented, for instance, in the pottery productions carried out in Galilee during the Iron Age and the Roman period (Shoval et al., 2006; Wieder and Adan Bayewitz, 1999) or currently in the community of potters settled in Pòrtol in Mallorca (Albero and Puerta, 2011).

Detecting clay mixtures can be extremely difficult in some archaeological ceramic records. It is impossible to detect this action through chemical analysis and, in fact, the mixture of different clays promotes significant alterations in the composition of the original raw materials. The resulting changes depend on the proportions of each type of clay mixed as well as their heterogeneity. Thus, clay mixing increases the compositional variability in the ceramics and hinders the establishment of reference groups. Although not always easy, thin section petrography is the best method to detect this action (Stoltman, 2001).

The main procedures available to detect clay mixtures are based, on the one hand, in the presence of clay pellets with particular and different characteristics regarding the clay matrix (Fig. 8.5 A). Also in the existence of clay veins in the fabric that provide a mottled appearance to the groundmass, with clays of different coloration, when it is observed under plane polarised light (Fig. 8.5 B). These differences between the colour of the clay matrix and clay relicts or veins are related to a divergent composition, such as different iron content (Kilmurry, 1982). On the other hand, the presence in the same vessel of microfossils such as foraminifera related to different geological periods and depositional environments is also reliable evidence that different clays were mixed (Albero and Mateu, 2012; Quinn and Day, 2007a). Finally, bimodal textural distributions in the clay matrix can be also related to the mixture of clays that have different textures (Velde, 2005). 
In short, even when the given several procedures are used we have to be very cautious to point safely to the mixing of different clays. On the one side, the presence in the paste of clay pellets and argillaceous rock fragments such as argillites or mudstones that have a differential composition with the surrounding matrix may occur within the clay deposit itself. Moreover, as already seen, these components may also have an anthropogenic origin as a consequence of the preparation of the paste. On the other hand, many clay deposits are unrelated to the marine or coastal environments in which foraminifera and other microfossils occur. Thus, in these cases, paleontological characterizations are completely ineffective to detect the mixture of clays. Finally, the presence of bimodal textural distributions in the paste can also be a consequence of the addition of temper in a well standardized grain-size. Therefore, the development of experimental reference collections with different types of clays and mixtures is needed to best approach the mixture of clays in pottery pastes. This experimental approach is useful to verify those features that can be unambiguously related to the mixture of clays of different provenances, thus allowing us to identify this action in archaeological ceramics.
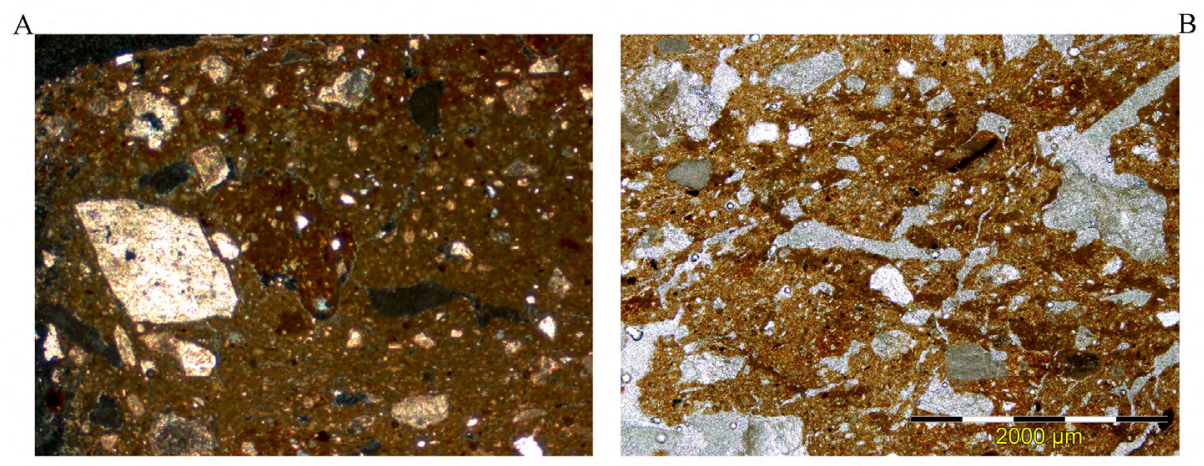

Figure 8.5: Thin section photomicrographs of $A$ ) textural feature concentrations with distinctive colour in cross polarised light (Image width $=1.75 \mathrm{~mm}$ ). B) A multi-coloured matrix in plane-polarised light (Image width $=4.9 \mathrm{~mm})$. 